\title{
CONTROLLING AND THE CLUSTERIZATION OF THE COMPETITIVE GENERATING ACTIVITY
}

\author{
Emil Chirilă ${ }^{1}$
}

\begin{abstract}
The complexity and dynamic of the organizations, which are in a permanent competition for resources and for the life quota in a turbulent economic environment, imposes the controlling as a functional concept of management having the role of coordinating the planning, control and information in the direction of obtaining the planned results. During 2008-2011, the National Council of Private Small and Medium Businesses in Romania is developing the NETIMM project, financed by European Social Fund through Human Resources Development Operational Programme 2007-2013. Starting from the technical, human resources and financial analysis of 15 companies from the construction sector located in the north-western region of Romania was sought to identify internal measures on which can be realized the generalization of the management techniques, by promoting controlling methods with external character regarding the development of associative cluster forms.
\end{abstract}

Key words: controlling, management system, enterprise, clusterization

JEL codes: G31, G30

\section{Introduction}

The contemporary period which is characterized by a fierce battle for resources in a globalized and competitive economy, required a reassessment of the place and role of business functions.

In these circumstances the financial function, from a simple technique derived from accounting, became a branch of economics known as "managerial finance" or "financial management" which is studying the "ensemble of economic and financial relations through which is constituted and used the capital of the enterprises in order to obtain and share the net profit"1 ensuring the achievement of the fundamental objective of private finance to: "maximize the assets accumulated in previous years, or to maximize the present value of expected future returns, since the main source of maximization is the net profit"2.

Are relevant in this context the questions raised in the literature and current practice related to the conduct of financial activity (Brealey-Myers, 1996) ${ }^{3}$ şi Sinkovics Alfred, $(2007)^{4}$ its place and role in ensuring a competitive management. For the Romanian economy which is characterized by a significant increase of the SME contribution to the GDP, are necessary to be imposed authentic measures to enhance management competitiveness and improvement of the management activity. In this context we consider relevant the implementation of an improved system of controlling, as an internal measure and cluster association, as external measure.

\section{Literature review}

The concept of controlling, resulting from the Anglo-Saxon economic environment and linked to the improvement with improvement of the managerial methods, is a concept "working with the task of coordinating the planning, control and information towards the desired results"(Horvarth \& Patners, 2005) ${ }^{5}$.

The concept has been assimilated into the European theory and practice by increasing of the

\footnotetext{
${ }^{1}$ University of Oradea, str. Universități nr. 1 Oradea, director@ crisanacons.ro
} 
American multinational companies activity since 1960 (Anthony\& Dodds, 1998) ${ }^{6}$ and in the Romanian scientific literature under the form of managerial-accounting control, "consisting of all its processes through which managers ensure that resources are obtained and used according to the organization's objectives and actions are progressing within the defined strategy"'(N. Tabără, 2006) şi (I.Ionaşcu, 2003) ${ }^{8}$.

Clusters are representing "loose associations of independent businesses from the legal and financial point of view, ensuring the promotion of innovation as a main component of investments and sustainable development" (Porter M, 1982) ${ }^{12}$. The current activity of the Romanian SMEs did not succeed to asimilate these theoretical concepts, fact for which are imposed genuine measures for information, learning and generalization, having as direct consequence an increase of their profitability and competitiveness.

\section{Research}

The controlling developed itself in the practical life of the enterprises becoming a management function, "functional concept with the role of coordinating the planning, control and dissemination towards the direction of obtaining the required results". It is realized a distinction between controlling as a function, the central task of the management and controller as responsible which has the role to coordinate the partial plans and to organize the entire planning process, contributing to the implementation of the strategic policy. At the small and medium enterprises, the controlling function is taken over by the management of the enterprise or by the accounting department, the controller transforming itself from a service supplier to a consultant of the management and involving its responsibility for achieving the objectives from different points of view:

o responsible for correctness of the collected and transmitted information;

$\circ$ through organization and supervising of the management process in order to achieve the objectives it contributes to the object oriented decision making of the management.

Transformation of the controlling in self-controlling is realized currently by training employees, at all levels, towards knowing and realizing the objective.

Each enterprise is following a certain strategy, for which its realization is guaranteed by a adequate structure adapted to the exploitation processes and realization of a an adequate organizational structure. The necessity of realization of its own controlling system supposes to answer to a collection of questions, like the following ones:

○ Do you know exactly from which products profit it's obtained and where are generated losses?

○ Do you know how various measures act over the result?

- Do you know how it looks your result analyzed over the business values of the company, without fiscal or balance sheet splitting?

- In your planning are included success oriented objectives and have proper allocated resources?

o How fast can you find out if you are still in the graph or you lost control?

- The need for decisions is established in time and all required measures are taken?

- Can you transpose the strategy of the enterprise in tangible plans oriented towards results and measures?

- Do you know factors which make you indirect costs to grow?

Implementation of the controlling systems is realized in the conditions of major challenges that contribute to changes in the economic and professional activities, financial accounting and are determined by ${ }^{9}$ :

○ Informational technologies more and more advanced

- Economic globalization and amplification of competition

$\circ$ Increase in the investment power from the capital markets. 
Organization of a controlling system at the level of an enterprise must have as objective assuring transparency as a premise for realization of an efficient management, which is guided on the following principles:

- Actions are oriented towards plan;

○ Individual, decentralized responsibility;

- Quantifiable management indices.

Realization of the controlling system supposes the integration of principles, instruments, organization and the controlling process in the structure of organization, in order to coordinate the information and planning system. The systemic organization of the management activity supposes orientation of the controllers' activities in two directions:

○ Towards the planning and control system, having as main component the budgeting;

o Towards the information system, having as main component the accounting.

Planning and reporting system, based on the accounting data, represents one of the most important fields of activity of the controlling. For a diagnostic it is imposed to answer to several questions regarding:

\section{THE ACCOUNTING}

The system of the expense account

- Ensures the differentiation between the fixed and variable costs?

- Are differentiated the relevant types of costs over their nature and destination?

\section{The centre of costs account}

○ The centers of cost are structured over clear defined fields of responsibilities?

- Unitary and adequate calculation procedures are used?

- Are realized systematically, planned, preliminary and effective calculations?

○ It exists a profit and loss account, on the short term, which is linked to the cost centers?

○ Can be determined the marginal revenues which are related to the adopted decisions?

\section{Allocation of costs in term of}

- Relations between the cost centers are adequately illustrated?

- In the generating chain of evaluation are used internal processes of discounting?

○ It exists a causal discounting of the costs between the cost centers?

\section{Result accounts}

○ It is realized and analyzed the result account in function of the evolution in time (for the entire financial exercise, at the finalization of activity for products with a long cycle of manufacture)?

- The result account reflects the evaluation generating chain at the level of enterprise?

- How differentiated (developed) is the result account?

\section{The investment calculation}

- Are used the adequate, unitary procedures for the calculation of the investment?

- The procedures are in conformity with the accounting directives and standards?

$\circ$ There is a consistency between the profit and loss account and the financial accounting.

- The synthetic analysis of the liquidities is used.

○ There is a link between the profit and loss account and planning

\section{REPORTING}

o Reporting is based on the data delivered by accounting? 
o The reporting system differentiates the data from the internal and external accounting?

o The reporting system is based on the automatic or manual data processing?

○ The reporting system assures the information according to the users' needs?

o The information delivered by reports is presented in a clear and understandable form?

o The information system delivers relevant information regarding deviations and causes?

○ On the basis of the reporting system are created measures of deviation removal?

\section{PLANNING}

- It exists a strategic planning in accordance with the operative planning?

- Planning is based on external information regarding forecasting of business revenue, competition analysis and technological trends?

- The operative planning systems are integrated in the financial planning (result account, balance sheet, capital flow)?

- The detail degree is adequate to the planning?

o The information delivered by planning are updated and used by the management?

- It is used the system of updating within a financial exercise?

- The implementation of the planning process has an internal regulation (budget manual)

The most important aspect of the regulatory circuit of the controlling is represented by the treatment of irregularities that should not be used as penalizing evidence for negligence of employees, but as a basis for establishing new measures. In this regard, a decisive role is taken by the reorganization of the entire system of costing calculation where the expenditures and incomes represent the "direct influence factor of the net situation"10 respectively increases in the own funding sources, while promoting efficient calculation methods for providing "decision-making information in real time"11.

Clusters can be formed in all sectors of economic life, both at national and regional level, being designated "a pole of competitiveness" in France and with the support of the European Commission, playing a key role in European cohesion policy and structural funds absorption. In 2007, through the Europe INNOVA Community Initiative was established the European Observatory of Clusters with the goal of gathering statistical data in order to develop indicators for measuring the dynamism of European clusters and to assess the impact of national and regional clustering policies.

In the cohesion policy clusters are one of the pillars of planning between 2007-2013, ensuring the promotion of innovation, as the main component of sustainable development and of the European investments. The Cluster is a territorial agglomeration of specialized and highly competitive businesses. It also means a concentration, clustering or spatial and territorial combination of small and medium-sized companies in an industry or inter-related fields of activities, which dominate the market (including the world market) in their area of specialization. It may be located in any type of local communities, from small (cities, communes, group of municipalities) to the regions in a state, state or regions belonging to border areas between countries.

The experience of developed countries has shown that clustering processes serve as a basis for constructive engaging in a dialogue between the representatives of the private and state organizations, the educational environment. It has allowed us to increase the efficiency of mutual relations, in the innovation process, between the private sector, state, trade associations, educational and research institutions.

For Romanian SMEs, clusters are loose associations of independent businesses from the legal and financial point of view, which, by recognized conventions, are establishing the conditions for participation in joint action to win public works or other funds, so that, by combining the prerequisite conditions regarding the equipment, personnel, experience, financial strength or size of 
contracts undertaken, could adjudicate the implementation of works which individually they cannot access. following ${ }^{12}$ :

The defining elements of the cluster type associations were defined by M.Potter(1992) as

\section{Particularities of the Cluster:}

1. is a limited form of regional economic activity within related sectors, linked to specific scientific institutions (universities, research and innovation centers, etc.).

2. are representing vertical rings (value chains) of production, specific to narrow sectors, in which the common stages of production are constituting the core cluster (the chain "supplier manufacturer - retailer - customer").

3. are industrial branches constituted at a high level of aggregation (eg "chemical cluster", "agro-industrial cluster").

\section{Specific character:}

1. identical or interrelated business areas;

2. fields of activities which can be diverse, where the economic activity becomes dominant and realizes high performances;

3. although there is a competitive relationship between the companies, they are also specialized on types, among them being produced a parallel phenomenon of cooperation and association in areas that are ensuring to all an increase of competitiveness;

4. between companies are occurring faster innovation phenomena, but also is created and a common infrastructure for innovation, where the universities and technology centers play an essential role

5. between companies exists an association capacity and relationships of trust maintained by an conducive cultural carrier environment, which reduces transaction costs and increases the competitive advantages.

6. areas of cooperation may be prepared professionally: management and marketing techniques, research - development and everything which involves strengthening the innovative capacity.

\section{Functional strategies in selection and elaboration of the Cluster:}

1. Initiation on spatial criteria of economic activities which are clustered at the local level (for example, fruit production in the Netherlands);

2. Horizontal: some industries/sectors can join in the context of broader clustering / (for example, the mega-cluster system within the Dutch economy);

3. Vertical: within the clusters can exist different stages of shared production

4. Side: in the cluster are unified different sectors which can ensure an global impact to the economy;

5. Technologic: the compatibility of the branches, which are using the same technology (eg. biotechnology cluster);

6. Focus: cluster of companies, focused on an central-enterprise, on a technology center or on an education institution;

\section{General strategies within the Cluster:} cluster

1. strategies aimed at increasing the level and applicability of existing knowledge in existing

2. strategies aimed at creating / initiating new cooperative networks within the cluster

The exchange of experience between 15 companies operating within the field of construction in North-Western Romania realized in the NETTIM Project, coordinated by the National Council of Private Small and Medium Enterprises in Romania and the exchange of experiences with similar companies in Germany in April 2010 in Munich, have helped the progress of negotiations to form a network of business associations, assuming the relevant also performance characteristics of cluster associations. 
In Figure 1 is shown the general scheme of operation of the associative network in construction industry from the North-Western Romania including also a presentation of internal and external functional relationships aimed at increasing competitiveness of affiliated businesses, by harnessing their human, technical and financial potential, by participation in tenders for public and private tenders, valorizing the competencies of all members and realization of premises for attracting European funding on behalf of the association.

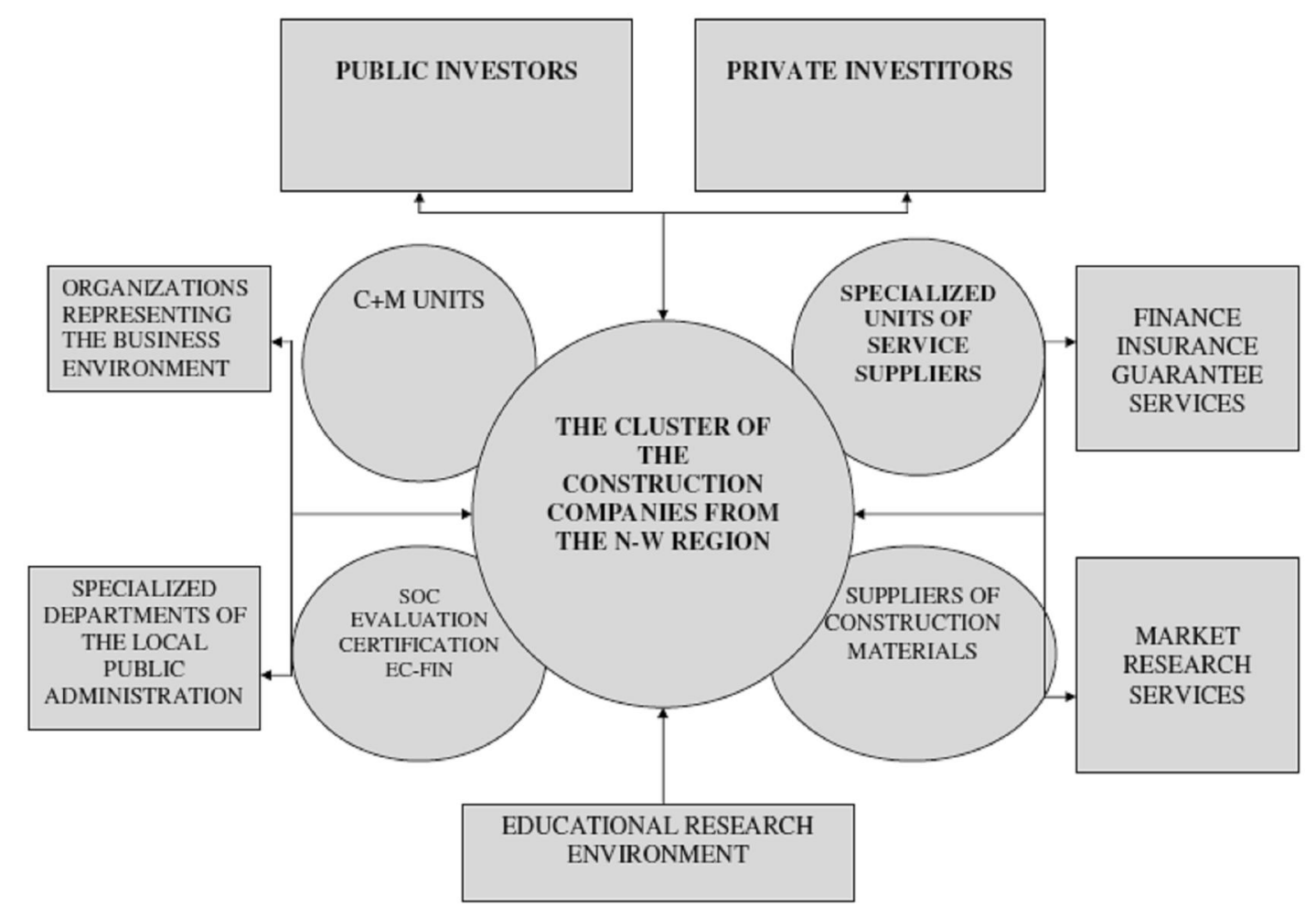

Figure no.1 -The general scheme of operation of the associative network construction

\section{Conclusion}

The approach of defining the main theoretical concepts of controlling and clustering can provide some reflections on the reorganization of the management system and valorization of competitive advantages through creation of networking associations to increase the performance of Romanian enterprises. This approach is being implemented by the formation of associative networks for the construction companies in north-western Romania within the NETTIM project, creating also premises for the generalization of managerial experience with favorable influences on profitability and competitiveness with the possibility of dissemination of this experience in other geographical areas.

\section{References}

1. Sighicea, N., Popescu, L., 2002. Gestiune financiară, Sitech Publishing House, Craiova, pag. 25

2. Stancu I. 2002. Finanțe, Economică Publishing House, București, pag 35

3. Brealey, Myers, Principles of corporate finance, 2005. Panem Publishing House, Budapest, pag.7 
4. Sinkovics A., 2007. Koltseg - es penzugyi Kontrolling, Complex Klado Jogi es Uzleti Tartalamszdgae tato kft, Budapesta, pag.79-85

5. Horvath \& Patners, 2007. Controlling. Sisteme eficiente de crestere a performantei firmei, C.H. Beck Publishing House, Bucuresti, pag. 4

6. Puxty A.G. \& Colin Dodds J., 1998. Financial Management Method and Meaning, Chapmn \&Hall Publishing House, First Edition London

7. Tabara, N., 2006. Modernizarea contabilitatii si controlul de gestiune, Tipo Polirom Publishing House, Iasi, pag.215

8. Ionascu, I., Filip Andrei, Stere, M., 2003. Control de gestiune, Economica Publishing House, Bucureşti

9. Andone, I.I., Tabara, N., 2006. Contabilitate, tehnologie si competitivitate, Academia Romana Publishing House, Bucureşti, pag.22

10. Ebbeken, K., Possler, L., Ristea, M., 2000. Calculatia si managementul costurilor, Teora Publishing House, Bucureşti, pag. 15

11. Kaplan, R.S., Cooper, R., 2001. Cost \&Effect using integrated cost system to drive profitability and performance, Hungarian Translation Panen, Budapesta,

12. Porter, M., 1982. The Competitive Advantage of Nations-London, The Mac Millan Press Ltd. 